doi https://doi.org/10.31977/grirfi.v21i3.2394

Recebido: 24/05/2021 | Aprovado: 15/09/2021

Received: 05/24/2021 | Approved: 09/15/2021

\title{
RESENHA
}

\section{A HISTÓRIA E O IMPOSSÍVEL: WALTER BENJAMIN E DERRIDA}

\section{Luciano Gomes Brazil ${ }^{1}$}

Universidade Federal do Rio de Janeiro (UFRJ)

(i) https://orcid.org/0000-0002-8000-3724

E-mail: brazil.filosofia@gmail.com

\section{RANGEL, Marcelo. A história e o impossível: Walter Benjamin e Derrida. Rio de Janeiro: Ape'Ku, 2020. (Coleção X).}

\footnotetext{
${ }^{1}$ Doutorando(a) em Filosofia na Universidade Federal do Rio de Janeiro (UFRJ), Rio de Janeiro - RJ, Brasil. Bolsista do(a): Coordenação de Aperfeiçoamento de Pessoal de Nível Superior (CAPES), Brasil.
}

RANGEL, Marcelo. A história e o impossível: Walter Benjamin e Derrida. Rio de Janeiro: Ape’Ku, 2020. (Coleção X). Resenha por Luciano Gomes Brazil. Griot : Revista de Filosofia, Amargosa - BA, v.21 n.3, p.438-447, outubro, 2021. 
O novo livro de Marcelo Rangel, “A História e o Impossível: Walter Benjamin e Derrida”, publicado em 2020 pela editora Ape'Ku, traz uma importante contribuição para o debate filosófico atual, que nos últimos anos tem se voltado intensamente para a crítica da violência e do direito.

O texto, que em verdade é a versão final de sua tese de doutorado, trata dos conceitos de modernidade e história na obra e no pensamento dos dois autores, o judeu alemão Walter Benjamin e o franco magrebino Jacques Derrida. Mas, eu diria que o tema central seja o conceito de justiça. Precisamos, no entanto, entender que Rangel não procede com a análise do conceito de justiça nas obras de Benjamin e depois nas obras de Derrida. Dividido em dois capítulos, lemos no título do primeiro: "Modernidade e História a partir de Walter Benjamin", enquanto para o segundo capítulo, lemos no título, "Modernidade, Justiça e História a partir de Derrida". O acréscimo do termo justiça (o itálico é nosso), parece, assim, ser o conceito que desequilibra as análises de ambos os autores. Sobretudo se levarmos em conta que para Derrida, "a desconstrução é a justiça", e que, justamente por causa dela, o autor franco magrebino ao mesmo tempo se aproxima e rompe com as teorias de Benjamin. Vejamos.

A primeira parte, que como já sabemos, trata de Walter Benjamin, traz em retrospecto três textos centrais da obra do teórico alemão sobre a modernidade e a história a partir do tema da narrativa. De início, Rangel trabalha com dois textos, "Experiência e Pobreza", escrito em 1933, e "O Narrador: Considerações sobre a obra de Nikolai Leskov", escrito em 1936; e, mais adiante, Rangel trabalha com um terceiro texto, o derradeiro "Teses sobre o conceito de História", de 1940.

Valendo-se de que os dois primeiros textos carregam uma determinada compreensão da modernidade, Rangel nos diz que eles abordam uma "percepção positiva acerca da possibilidade de rearticulação da modernidade" (RANGEL, 2020, p.31). Para isso devemos nos perguntar: o que há com a modernidade? Respondemos citando o autor: ela é um "momento de diferenciação (transformação) radical da história". Esta diferenciação, que é um traço inerente da história, encontra na modernidade uma tal intensificação, aceleração, que

\footnotetext{
se por um lado, até a primeira metade do século XIX, os homens em geral se relacionavam entre si e com o seu horizonte histórico (ou realidade efetiva) a partir de certa imediatidade ou intimidade, o que, por conseguinte, assegurava certa estabilidade à história, por outro lado, a partir da segunda metade do século XIX e início do século XX, de acontecimentos como a Primeira Guerra Mundial, temos a irrupção de contextos e conjunturas inéditas em relação as quais os homens e mulheres em geral não sabiam como se comportar, o que acabara provocando uma instabilidade significativa, uma desarticulação da própria imediatidade e, por conseguinte, de determinado mundo compreendido aqui como um conjunto sedimentado e geral (transcendental) de sentidos, significados e afetos. (RANGEL, 2020, p.31-32).
}

Um traço característico desta aceleração, que retira dos indivíduos uma certa estabilidade e homogeneidade na relação com o mundo, é o hiato entre as gerações. As mudanças ocorrem tão depressa que não é mais possível que haja uma transição, poderíamos talvez dizer, uma continuidade, entre as gerações, e por isso Benjamin percebe que a modernidade

\footnotetext{
acentuou e produziu conjunturas em relação as quais os homens em geral não sabiam como se comportar, reduzindo as possibilidades disto que Benjamin chama de 'experiência', ou seja, da relação com/tematização da realidade a partir de um conjunto de sentidos, significados, afetos sedimentados e adequados. (RANGEL, 2020, p.35).
}

Por isso que homens e mulheres em geral, a partir das circunstâncias apresentadas

\footnotetext{
RANGEL, Marcelo. A história e o impossível: Walter Benjamin e Derrida. Rio de Janeiro: Ape’Ku, 2020. (Coleção X). Resenha por Luciano Gomes Brazil. Griot : Revista de Filosofia, Amargosa - BA, v.21 n.3, p.438-447, outubro, 2021.
} 
tornaram-se "pobres de experiência", tese central do primeiro texto, "Experiência e Pobreza". A I Guerra Mundial foi o evento decisivo deste empobrecimento, "pois os combatentes voltavam silenciosos do campo de batalha". Esta constatação de empobrecimento, na época em que os textos foram escritos, foi compensada por uma evidenciação e compreensão otimista do movimento deveniente. Isto é, se o passado e presente daquela modernidade testemunhada por Benjamin desarticulara certa estabilidade sedimentada, por outro lado, era a chance da transformação, rearticulação destes mundos. Dito isto, a escrita de Rangel segue os passos de Benjamin, primeiro ao esmiuçar um tipo de pathos/afeto propício a esta rearticulação positiva da história na modernidade. Trata-se da modéstia, do contentar-se com pouco. Mas isto por que? Porque a intensificação das transformações no âmbito da modernidade obriga-nos a conviver com o fragmentário. Contentar-se com pouco seria aquilo que alguns dos grandes criadores se obrigaram a realizar, pois "operaram a partir de uma tábula rasa" (BENJAMIN apud Rangel, 2020 , p.39). Este pathos que reconfigura a história, no entanto, não é uma exigência característica da modernidade, mas sim algo constitutivo da própria história, aquilo que o próprio Benjamin chama de Jetztzeit (tempo do agora):

Quando esse instante propício à reorganização da história se abre, cabe aos homens e
mulheres, por sua vez, se posicionarem - hiperempírica e coletivamente - no sentido de
tornar-se um âmbito (uma atividade) adequado à intensificação e realização de
determinada reconfiguração ou diferenciação em andamento, abrindo-se a possibilidade
do que Benjamin chama em seu "Experiência e Pobreza" de "criação" (RANGEL, 2020,
p.40).

Rangel assinala três características da ética da modéstia: (1) suspensão por toda e qualquer orientação prévia, quer seja da cólera ou indignação improdutivas, ou o hedonismo/egoísmo onírico propiciado pela técnica; (2) uma (hiper) exposição em relação ao horizonte histórico, isto é, uma experiência de exposição radical a despeito de quaisquer garantias, uma vez que se lança por sobre qualquer orientação prévia; (3) retenção de certa alegria, paradoxalmente conquistada a partir de um reconhecimento de "que é hoje em dia uma prova de honradez confessar nossa pobreza".

Certamente este relativo otimismo modula e ganha uma dimensão mais profunda a partir do ensaio "O Narrador", que segundo Rangel não pode ser dito como um ensaio exatamente otimista, e onde se constata que "a experiência da arte de narrar está em vias de extinção". Aqui, aquela instabilidade característica da modernidade é centralizada a partir da figura do narrador, que de algum modo não seria mais próprio ao horizonte contemporâneo, "inicialmente porque se tratava de um mundo em crise [...], para o qual ou a partir do qual os sentidos, significados e afetos mais gerais [...] se mostravam inadequados (logo desinteressantes). (RANGEL, 2020, p.52). Mas o tom mais melancólico, e, portanto, menos otimista, se mostra na evidenciação da supressão da própria atividade de narrar, "a experiência de que a arte de narrar está em vias de extinção" (BENJAMIN apud RANGEL, 2020, p.53).

Segundo Rangel, a narrativa é responsável pela intimidade entre linguagem e realidade, e que, portanto, ela "não se constitui a despeito de determinado espaço mais empírico [...] mas sim a partir dele, junto a ele" (RANGEL, 2020, p.55). Por isso se pode dizer que, por um lado, ela se constitui

por um campo mais geral de sentidos, significados e afetos, a partir do qual as experiências (mais singulares, inclusive) se constituem, mas, também, por um outro, como um horizonte em movimento (em diferenciação) na medida em que vai acolhendo outras experiências possíveis (RANGEL, 2020, p.55),

RANGEL, Marcelo. A história e o impossível: Walter Benjamin e Derrida. Rio de Janeiro: Ape’Ku, 2020. (Coleção X). Resenha por Luciano Gomes Brazil. Griot : Revista de Filosofia, Amargosa - BA, v.21 n.3, p.438-447, outubro, 2021. 
figurados nas imagens do camponês sedentário ("que conhece suas histórias e tradições" (BENJAMIN apud RANGEL, 2020, p.56)), figura tipológica da estabilidade, e do "marinheiro comerciante" (pois "quem viaja tem muito a contar" (BENJAMIN apud RANGEL, 2020, p.56)), figura tipológica da alternância, novidade.

Há, a partir da questão da narrativa, colocada por Benjamin, uma terceira forma de "comportamento inadequado à experiência de tempos críticos como a modernidade" (RANGEL, 2020, p.57): o surgimento da forma literária do romance. Diz o autor berlinense que "A origem do romance é o indivíduo isolado, que não pode mais falar exemplarmente sobre suas preocupações mais importantes e que não recebe conselhos nem sabe dá-los" (BENJAMIN apud RANGEL, 2020 , p.57). Dito isto, podemos afirmar que o romance é a forma narrativa que se constitui a partir de uma perda da forma narrativa coletiva, e que, portanto, contribui para a instabilidade característica da modernidade: "O romance é escrito e também lido (ou consumido) solitariamente, e distante da tensão entre determinadas tradições e experiências mais singulares, de modo que ele não é capaz de rearticular a realidade de maneira adequada" (RANGEL, 2020, p.58). Também a forma jornalística é inadequada para constituir uma narrativa porque não dá conta de estabelecer um horizonte crítico, limitando-se a uma situação curiosa e ao consumo, não oferecendo uma explicação abrangente.

Mas então, o que constitui aquele certo otimismo em face de uma estabilidade que poderia se reconstituir? Rangel nos explica que naquele momento, da escrita dos dois ensaios, Experiência e Pobreza e $O$ Narrador, Benjamin concebia a modernidade como um "tempo radicalmente acelerado, em movimento de deveniência, o qual também se constituía, portanto, como uma espécie de antessala a partir da qual um espaço organizado (e diferenciado) se tornaria possível". (RANGEL, 2020, p.61).

Neste sentido, e a despeito de o ensaio "O Narrador" não ser "exatamente otimista, ele, juntamente com "Experiência e Pobreza" fazem uma leitura da modernidade como uma época de "um tempo deveniente profundamente acelerado, instável" (RANGEL, 2020, p.61) cuja instabilidade é propícia ao âmbito a partir do qual "qualquer estabilidade" pode se reconstituir. Mas, nesse caso, neste ensaio posterior, Benjamin investe em "outro comportamento adequado", em outro, por assim dizer, afeto, o tédio: "Se o sono é o ponto mais alto da distensão física, o tédio é o ponto mais alto da distensão psíquica. $O$ tédio é o pássaro do sonho que choca os ovos da experiência" (BENJAMIN apud RANGEL, 2020, p.62). Este tédio, segundo Rangel, é o que torna possível

\footnotetext{
1) a concretização da estratégia ideal à experimentação de tempos críticos, a saber, o acompanhamento atento (e paciente) do que desponta; e 2) torna possível, ainda, uma atividade que é fundamental à narrativa: a audição, tendo em vista que todo narrador precisa ser um ouvinte extraordinário, precisa ter a paciência para isto que é ouvir (e ter que contar)" (RANGEL, 2020, p.62)
}

Rangel, na sequência, tematiza o derradeiro escrito de Walter Benjamin, os fragmentos que ficaram conhecidos como as "Teses sobre o conceito de História". Tem-se como ponto de partida o tom melancólico que marca o texto já desde sua primeira tese, o que faz com que a leitura da história e da modernidade seja acompanhada do tema da melancolia, ou seja, constitui a historicidade moderna algo que se denomina por melancolia e que, de todo modo, diz respeito a algo que já vinha sendo dito nos textos anteriores de Benjamin, em específico aqueles dois ensaios que tematizamos acima, qual seja, a da experiência de uma perda, e não tão somente isto mas bem como, para utilizar a expressão de J.M Gagnebin, "a produtividade da perda". Mas se o tom

RANGEL, Marcelo. A história e o impossível: Walter Benjamin e Derrida. Rio de Janeiro: Ape’Ku, 2020. (Coleção X). Resenha por Luciano Gomes Brazil. Griot : Revista de Filosofia, Amargosa - BA, v.21 n.3, p.438-447, outubro, 2021. 
melancólico já está presente nos textos de Benjamin, o manuscrito de 1940 possui um tom ainda mais profundamente melancólico, isto é, as teses "se constituem a partir da tarefa da explicitação e retenção do caráter de possibilidade da história, mas isto melancolicamente, ou seja, sem que o próprio Benjamin acreditasse que isto pudesse se concretizar mais propriamente" (BENJAMIN, 2020, p.22).

Se observarmos a sequência dos capítulos do livro, após dar início ao tópico que tematiza as Teses sobre o conceito de História, Rangel propõe uma antropologia benjaminiana, ligada à história, e, neste caso, isto incide em afirmar que "homens e mulheres em geral são orientados pelo 'decurso da existência' (der Verlauf unseres eigenen Dasein), ou ainda, pelo passado" (RANGEL 2020, p.69).Ou seja, a imagem da felicidade, ligada a cada indivíduo, é mobilizada pelo passado (RANGEL, 2020, p.69). Esta configuração antropológica parece ser decisiva para se colocar plenamente o problema do conceito de história, e que necessariamente acompanha a crítica ao progresso, crítica esta tão característica do pensamento de Benjamin:

[...] Os homens e mulheres em geral são compreendidos como espaços próprios ao acolhimento dos 'apelos' que advém de passados obscurecidos, e isto porque são uma estrutura dotada de uma determinação específica que é a da 'exposição' em direção, ao encontro, desses passados. Em outras palavras, se bem esses passados se remetem ao presente, é preciso que eles sejam acolhidos, e isto se dá justamente em razão de os homens e mulheres serem estruturas dotadas da capacidade de acolher os 'sussurros' liberados pelo passado". (RANGEL, 2020, p.71)

Esta constituição antropológica permite que seja pensada uma historiografia benjaminiana "compreendida aqui como tematização e produção de enunciados a partir de passados" que tornaria possível retomar passados obscurecidos e fazendo com que se tornasse possível:

1) a própria lembrança do caráter de possibilidade da história, ou ainda, que todo e qualquer mundo é apenas um mundo possível (que muitos já existiram e que outros ainda se conformarão), o que seria fundamental no interior de um horizonte histórico determinado pela ideologia do progresso e sua compreensão teleológica e monolítica da história, e 2) a liberação de conteúdos e afetos adequados ao questionamento de determinado presente ou conjuntura sedimentada (e congelada), e isto de forma a provocar a diferenciação da história. (RANGEL, 2020, p.75)

Por fim, Rangel cruza esta constituição do sentido benjaminiano de história como restituição de passados obscurecidos com a noção geral de crítica tal como encontramos na obra e no pensamento de Benjamin:

A historiografia a partir de uma perspectiva benjaminiana se aproxima radicalmente da filosofia, da crítica literária e da crítica de arte em geral, e isto porque elas são (seriam) atividades dedicadas, ao fim, a uma mesma tarefa fundamental, a de criticar interpretações (ou "bens culturais") mais gerais constituídas no interior da própria historiografia, da crítica literária, da crítica de arte e da (história da) filosofia, por exemplo (RANGEL 2020, p.88).

É a partir daí que o escrito de Rangel faz o pensamento de Benjamin, em específico este pensamento "mais melancólico", de um teórico em vias de fuga e aterrorizado pela experiência do fascismo se aproximar do pensamento de Derrida. Aproximação esta que ocupa a parte central da tese de Rangel, a tal ponto que, nas suas palavras, "Derrida e Benjamin parecem se confundir" (RANGEL, 2020, p.28). Mas, é que, uma vez definido um certo aspecto comum entre a 
historiografia e a crítica, Marcelo Rangel faz um salto de volta a 1921 e ao ensaio "Para a crítica da violência". É que a tese VIII, isto no texto de 1940, nos diz que "A tradição dos oprimidos nos ensina que o 'estado de exceção', no qual vivemos é a regra. Precisamos chegar a um conceito de história que dê conta disso" (BENJAMIN apud RANGEL, 2020, p.92). Ora, mas é no ensaio "Para a crítica da violência" que encontramos algumas formulações acerca da modernidade que parecem terem sido aproveitadas quase vinte anos depois, em específico este acerca do estado de exceção. São estas formulações que se aproximam da desconstrução derridiana como veremos a seguir.

Segundo Rangel (2020, p.93), há dois atributos possíveis do estado de exceção, um, que seria o "próprio", que traria a "possibilidade de uma suspensão efetiva no interior de determinado horizonte histórico sedimentado (e congelado)", e outro, "impróprio", "se refere à repetição incessante de comportamentos 'extraordinários' (extralegais) gerados a partir do Estado". O que ocorre é que este segundo tipo de exceção faz repetir uma dada ordem, provocando a "permanência/repetição de determinado (sic) aspecto ou horizonte histórico". A marca geral do pensamento de Benjamin como crítica ao progresso está intimamente ligada a esta questão, pois

a modernidade e, em seu interior, todo e qualquer aspecto, entre eles o fascismo em geral
e a própria democracia parlamentar, se constituíram a partir da ideologia do progresso
[...]. De modo que os fascismos ou a democracia parlamentar justificavam (e justificam)
a sua existência e todo e qualquer comportamento 'extraordinário' (mais recorrentes do
que boa parte de nós pode perceber) com base no imperativo da consecução do progresso.
Trata-se, assim, de uma espécie de normalização de comportamentos 'extraordinários'
(um estado de exceção 'impróprio') com o objetivo de proteger e perpetuar os espaços no
interior (e através) dos quais isto que seria o progresso da humanidade seria possível: o
Estado, a lei, a polícia [...] (RANGEL, 2020, p.94)

Evidenciar o "caráter ideológico do progresso" a fim de mostrar que nele está contido um perigo, qual seja, o de eliminar de vez o caráter de possibilidade da história, seu caráter contingente, por uma narrativa que se coloque como "necessária", é tarefa do historicismo e da crítica benjaminiana. Neste sentido, o capítulo central do livro de Marcelo Rangel é aquele que trata diretamente da leitura derridiana de Benjamin. Em "Força de Lei", o pensador francomagrebino interpreta o ensaio "Para a crítica da violência". Este ensaio tem uma importância à parte, devido a uma noção de justiça que está ali colocada por Benjamin.

Mas, nesta altura, devemos nos perguntar: que relação há entre as teses sobre o conceito de história, a crítica da violência e a desconstrução derridiana? Já vimos, linhas acima, o que há em comum entre os dois textos benjaminianos. E se nos fiarmos aos títulos dos capítulos do livro de Marcelo Rangel, como vimos no início desta resenha, leremos que o capítulo um chama-se "Modernidade e história a partir de Walter Benjamin", e o capítulo dois chama-se "Modernidade, justiça e história a partir de Derrida", o que nos levaria a crer que aquilo que distinguiria o pensamento de Derrida do pensamento de Benjamin seria algo relacionado à justiça. Em primeiro lugar, deve-se anotar o sentido metafísico de justiça, a saber "a justiça como instauração de uma ordem ideal a todas as partes" (RANGEL, 2020, p.111) a qual Derrida procura desvincular de uma relação necessária com a desconstrução: "A desconstrução e a possibilidade de justiça': a conjunção $e$ associa palavras, conceitos, talvez coisas que não pertencem à mesma categoria" (DERRIDA apud RANGEL, 2020, p.111). É que o texto derridiano que está em jogo diz respeito a uma apresentação em um colóquio que ele fora convidado e que deveria tratar da relação entre desconstrução e justiça, o que quer dizer, tratar-se-ia de uma apresentação que carregaria consigo um determinado entendimento acerca do que seria isto, a justiça: "o colóquio constrangeria seus convidados a intensificar, de algum modo, a compreensão metafísica de justiça. Seria isto que

RANGEL, Marcelo. A história e o impossível: Walter Benjamin e Derrida. Rio de Janeiro: Ape’Ku, 2020. (Coleção X). Resenha por Luciano Gomes Brazil. Griot : Revista de Filosofia, Amargosa - BA, v.21 n.3, p.438-447, outubro, 2021. 
Derrida faria se aceitasse, por exemplo, relacionar, imediatamente, desconstrução à justiça" (RANGEL, 2020, p.114).

No entanto, como diz Rangel,

o filósofo anota que ele, que sua participação no congresso, que a própria desconstrução não pode, nunca pôde, ser justa no sentido metafísico, ou ainda, que não é possível objetivar todo e qualquer constrangimento, para suspender-se em relação a um horizonte de base específico e, por conseguinte, elaborar uma reflexão e enunciados imparciais (RANGEL, 2020, p.114).

Por isso, a desconstrução "é apresentada aqui, como um exercício crítico (que expõe) mas que também é (quase) transcendentalmente determinado e, por isso, também posicionador, arbitrário e violento" (RANGEL, 2020, p.114-115). Por esse caminho alcançamos Benjamin no que ele dizia em Para a crítica da violência ao manter afastado direito e justiça e de fazer mostrar que ao direito cabe a conservação de um tipo ou horizonte específico de possibilidade e o impedimento de assunção de outros horizontes. No entanto, Rangel curiosamente não afirma que a aproximação Derrida-Benjamin se dá pelo entendimento sobre o direito, mas antes, esta aproximação se dá pelo entendimento da justiça, isto porque "o filósofo alemão é profundamente ambíguo em relação à noção de justiça" (RANGEL, 2020, p.119-120).

Precisaremos aqui tomar um fôlego para continuarmos. Dizíamos que Benjamin, em 1940, ao escrever as teses sobre o conceito de História, estava preocupado, uma vez que o caráter ideológico do progresso contém um enorme perigo, qual seja, de abalar as características mais intrínsecas à história, seu caráter de possibilidade. Isto porque as narrativas progressistas se referem a uma sucessão de fatos como sucessão necessária, não casual. Estas narrativas progressistas tendem a aniquilar, portanto, tudo aquilo que não faz parte ou que devem ser suprimidos na linha do progresso da história. E é por este motivo que a social democracia não seria menos perigosa que o próprio fascismo, pois ambas comungam da mesma ideologia do progresso. Em vez disto, uma história que não parta desses pressupostos, e que, portanto, não distinga pequenos acontecimentos dos grandes, seria mais pertinente na luta contra o fascismo. Vimos também que as teses sobre o conceito de história propõe a constituição de um estado de exceção "apropriado" à demanda de uma história enquanto possibilidade. Esta noção de exceção é pelo menos uma das ligações possíveis com o texto escrito décadas antes, Para a crítica da violência, onde Benjamin critica o direito e o estado constitucional, parte integrante de sua crítica geral à modernidade política.

$O$ ponto de contato e de certa continuidade entre o trabalho pensante de Benjamin e o de Derrida começa pela desconstrução derridiana do direito: "Derrida irá afirmar que o direito é responsável pela imposição de determinado horizonte mais ou menos sedimentado em relação a outros (à alteridades), e isto através da 'aplicação' de determinados juízos e enunciados" (RANGEL, 2020, p.118). Ou seja, se o direito é adequado e justo a "certo horizonte", “ele é, necessariamente, inadequado, injusto e impróprio a outras relações" (RANGEL, 2020, p.118). Havíamos, porém, comentado, que Derrida entende que Benjamin é profundamente ambíguo em relação à justiça. É que ambos se articulam a partir de uma distinção fundamental entre direito e justiça, cabendo nesta distinção a questão se pode a justiça ser concebida de algum modo que não seja nem arbitrária, nem violenta. E é quase ao mesmo tempo em que Benjamin e Derrida tanto se assemelham, que o franco-magrebino anota sua crítica ao escritor berlinense. Para ele, Benjamin tenta responder positivamente sobre a possibilidade de uma justiça não arbitrária e não violenta, aquilo que ganhou, no texto de Benjamin, o termo de "violência divina", "o que se torna motivo importante para a crítica do filósofo franco-magrebino, que o situa, inclusive, ao lado de

RANGEL, Marcelo. A história e o impossível: Walter Benjamin e Derrida. Rio de Janeiro: Ape'Ku, 2020. (Coleção X). Resenha por Luciano Gomes Brazil. Griot : Revista de Filosofia, Amargosa - BA, v.21 n.3, p.438-447, outubro, 2021. 
Heidegger e Carl Schmitt, acusando-o de participar e de intensificar uma atmosfera específica a partir da qual os fascismos em geral teriam se constituído" (RANGEL, 2020, p.121). Em outras palavras, no livro Força de Lei, Derrida critica Benjamin por, ao tentar dar uma resposta positiva acerca da justiça, ter proposto um horizonte de possibilidade propício ao fascismo. Isto porque, se por um lado, Benjamin apresentara, em Para a crítica da violência, um conceito de violência divina, que deporia o direito (e sua arbitrariedade), por outro, o próprio Derrida, por sua vez, se pergunta "pela possibilidade de termos alguma justiça e, por conseguinte, algum direito, que não sejam uma simples intensificação de determinado horizonte (quase) transcendental em detrimento de outros" (RANGEL, 2020, p.123). O capítulo 2.1.2 Justiça, adequação e direito (RANGEL, 2020, p.118-135), certamente o mais denso do livro, começa pela aproximação/distanciamento de Derrida com Benjamin e termina com a interpretação derridiana do conceito de Justiça, em Heidegger. Isto para dizer algo intrínseco ao próprio pensar e a toda e qualquer ação: "todo e qualquer pensamento e ação, enunciados e acordos são, mais propriamente, a intensificação de determinado horizonte (quase) transcendental, sendo, por conseguinte, arbitrários e violentos" (RANGEL, 2020, p.135-135).

Nesta direção, torna-se ainda mais premente a desconstrução derridiana e que, em algum momento se encontra, ou poderia se encontrar, por fim, com a justiça em sentido não metafísico, uma vez que ela é uma experiência de aporia. Restituir esta experiência de aporia seria aquilo que é mais propício aos filósofos, sem fazer crer, porém, que sua atividade, tal como todas as outras, não termine por investir em algo que seja também arbitrário e violento. Sob este ponto de vista, a crítica a Benjamin recai no conceito de "violência divina" porque ela, mesmo que de algum modo aporética, restitui ou clama por um sentido metafísico e, portanto, não desconstruído, de justiça.

Hoje, décadas depois, sabemos que talvez Derrida tenha sido injusto com relação a Benjamin, em Força de Lei. Esta conclusão, porém, se dá em favor da própria desconstrução. Para Derrida, o termo Gewalt utilizado tanto para poder quanto para violência remete Benjamin a uma dimensão metafísica de justiça, atribuindo a um ente transcendente o poder de destituição do direito, o que faria Benjamin se movimentar no interior da compreensão daquilo que ele próprio estava pondo em crítica, qual seja, a constituição naturalizada do direito e do estado moderno. Benjamin

também se mantinha profundamente orientado por este horizonte histórico (que criticara) na medida em que explicitava (e ratificava) que: a) haveria sim uma violência justa (autorizada), a 'divina', e b) que através dela um horizonte histórico ideal viria a ser constituído. $O$ traço distintivo desta 'violência' seria, portanto, a compreensão de que a instauração de um horizonte histórico novo e ideal dependeria da atividade e intervenção divina. (RANGEL, 2020, p.186)

\section{Derrida "contra, a partir, junto, em conjunto com Benjamin"}

Tenhamos em conta que a aproximação entre Benjamin e Derrida realizada por Marcelo Rangel não trai a perspectiva desconstrucionista derridiana. Isto é, a aproximação, a ponto de quase uma con-fusão entre um e outro não é algo que se encontra fora do texto derridiano, mas que é inerente a seu pensamento. Por isso Rangel diz que "Derrida dará um passo a mais no que tange à tematização e explicitação do pensamento ou do gesto crítico benjaminiano" (RANGEL, 2020, p.192). E completa: "É como se Derrida se dedicasse à evidenciação de uma espécie de espirito que animaria o texto de Benjamin" (RANGEL, 2020, p.192). Isto é possível porque, segundo ele, "podemos compreender o movimento de desconstrução derridiano como um exercício

RANGEL, Marcelo. A história e o impossível: Walter Benjamin e Derrida. Rio de Janeiro: Ape’Ku, 2020. (Coleção X). Resenha por Luciano Gomes Brazil. Griot : Revista de Filosofia, Amargosa - BA, v.21 n.3, p.438-447, outubro, 2021. 
de responsabilidade e de amizade" (RANGEL, 2020, p.192), em que se procura "explicitar aquilo mesmo que o autor poderia ter dito, mas que não foi suficientemente constituído a partir de sua narrativa" (RANGEL, 2020, p.192).

No caso específico de Força de Lei, esta perspectiva pode ser lida como uma continuação/intensificação do próprio texto criticado, neste caso, Para a crítica da violência, de 1921, “que se insere numa espécie de posicionamento ético que aponta para a possibilidade ou mesmo necessidade de se dedicar à continuação de perspectivas obscurecidas, periferizadas no interior do próprio texto criticado" (RANGEL, 2020, p.192). É isto que faz Derrida ler o texto, questionando "o direito, a lei, contra, a partir e junto, em conjunto com Walter Benjamin" (RANGEL, 2020, p.194). A frase de Benjamin de que "há algo de podre no direito", que Derrida retira do texto para seguir um caminho encontrado pelo autor alemão, qual seja, a de que o estado e o direito modernos se valem do monopólio da violência, sob a promessa de que ela seria o meio que garantiria um mundo ideal, ao mesmo tempo em que suprime qualquer outra possibilidade (em específico, individual) de aparecer, faz con-fundir (Derrida contra, a partir, junto, em conjunto com Benjamin) a desconstrução com a crítica da violência.

Esta con-fusão entre ambos se dá na direção do entendimento disto que opera, no pensamento de Benjamin, de modo messiânico, como uma "tendência à diferenciação". Por isso diz Derrida que "Essa referência súbita a Deus, acima da razão e da universalidade, para além de uma espécie de Aufklärung do direito, não é outra coisa, parece-me, senão uma referência à singularidade irredutível de cada situação" (DERRIDA apud RANGEL, 2020, p.198). E, assim, se pode afirmar do Deus de Benjamin como uma "hipótese melancólica". Sim, uma "hipótese melancólica" que em vez de chancelar um fundamento místico da autoridade, "pretende resguardar desesperada e 'loucamente' a possibilidade de que o horizonte histórico se rearticule" (RANGEL, 2020, p.199). Desesperada e loucamente porque desesperançada, por isso, melancólica. Qual a possibilidade de uma rearticulação da história cuja violência e arbitrariedade não sirvam de meio para uma dada configuração? Por isso diz Rangel, afinado com o pensamento derridiano: "Benjamin resguardaria o lugar do 'impossível', do absolutamente inesperado e imprevisível" (RANGEL, 2020, p.198). Trata-se da intimidade entre o inteiramente outro e o diferimento ${ }^{2}$, que são tão caros ao pensamento de Derrida. Encerremos com uma situação oportuna do autor francomagrebino:

Qual o último e mais provocador paradoxo dessa crítica da violência? Aquela que dá mais a pensar? É que essa crítica se apresenta como a única "filosofia" da história (a palavra "filosofia" permanecendo entre aspas inesquecíveis" que torne possível uma atitude não apenas "crítica', mas, no sentido mais crítico e diacrítico da palavra "crítica", do krinein, uma atitude que permite escolher (Krinein), portanto decidir e resolver na história e a respeito da história. É a única que permite uma relação com o tempo presente, anota Benjamin, uma tomada de decisão discriminante, decisória e decisiva (scheidende und untscheidende Einstellung). Toda a indecidibilidade (Unentscheidbarkeit) está situada, bloqueada, acumulada no lado do direito... Toda decidibilidade, ao contrário, se situa no lado da violência divina, que destrói o direito, poderíamos mesmo arriscar dizer que desconstrói o direito [...] (DERRIDA apud RANGEL, 2020, p.201).

\footnotetext{
2 Cf.notas 113 e 114, que ficam à página 199 e 200. Diz Rangel: "o pensamento derridiano guarda uma relação de profunda intimidade com o pensamento medieval e com a teologia negativa (e ainda com Lévinas e a fenomenologia, neste caso em razão do tema da transcendência (mistério) inesgotável, em especial em razão de reter delas as experiências do inteiramente outro e do "segredo", e, ainda, certa aposta na reorganização recorrente da história, no porvir, e isto de forma a resguardar certo diferimento (e autonomia) à própria realidade".
}

RANGEL, Marcelo. A história e o impossível: Walter Benjamin e Derrida. Rio de Janeiro: Ape'Ku, 2020. (Coleção X). Resenha por Luciano Gomes Brazil. Griot : Revista de Filosofia, Amargosa - BA, v.21 n.3, p.438-447, outubro, 2021. 


\section{Referências}

RANGEL, Marcelo. A história e o impossível: Walter Benjamin e Derrida. Rio de Janeiro: Ape'Ku, 2020. (Coleção X).

Autor(a) para correspondência / Corresponding author: Luciano Gomes Brazil. brazil.filosofia@gmail.com 